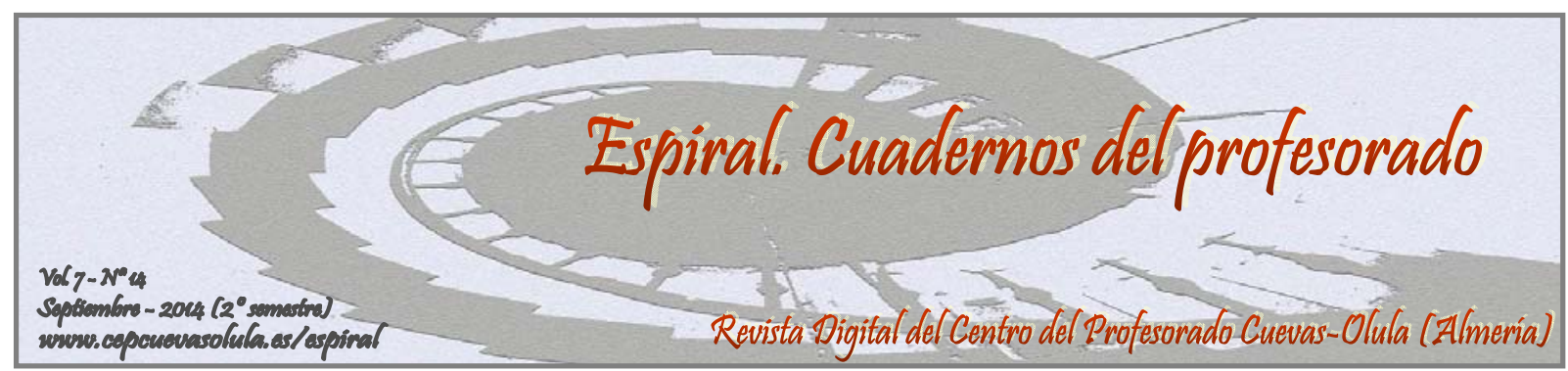

\title{
PAUTAS ORGANIZATIVAS DEL AULA DE MÚSICA DE SECUNDARIA PARA ATENDER A LA DIVERSIDAD CULTURAL: PROPUESTAS DIDÁCTICAS
}

\section{ORGANIZATIONAL PATTERNS IN HIGH SCHOOL MUSIC CLASSROOMS TO ADDRESS CULTURAL DIVERSITY: DIDACTIC}

\section{María del Mar Bernabé Villodre}

Universidad Católica de Murcia, Murcia, España

\begin{abstract}
RESUMEN: El aumento de la diversidad cultural presente en las aulas de Educación Secundaria trajo consigo una revisión de los contenidos curriculares de la legislación, cuando este alumnado, culturalmente diverso, fue visto como una numerosa y problemática realidad, que comenzó a demandar una educación de calidad y en condiciones de igualdad. La asignatura de Música sufrió muchos cambios que pudieron observarse, principalmente, en sus contenidos conceptuales; estos cambios le llevaron a convertirse en el centro neurálgico de la posible actividad intercultural que pudiese desarrollarse en el centro de enseñanza obligatoria. Desde este artículo se pretende mostrar cómo debe organizarse el aula de Música (espacio, materiales, actitudes, valores y contenidos) para que el proceso educativo musical se convierta en un proceso educativo intercultural. A modo de conclusión, se incluyen unas propuestas didácticas basadas en el trabajo cooperativo como principal herramienta de intervención educativa intercultural musical. Se ha partido de la consideración de que la comunicación entre culturas será una realidad gracias a la práctica de la interpretación musical que es cooperativa por naturaleza, así como gracias al estudio crítico del lenguaje musical comprendido como lenguaje universal de comunicación entre los pueblos.
\end{abstract}

Palabras clave: diversidad cultural, interculturalidad, música, educación musical

ABSTRACT: Increasing cultural diversity present in High School brought a revision of the curricula of law, when culturally diverse student was seen as a large and problematic reality that began to demand quality education and conditions equality. The subject of Music underwent many changes were observed mainly in its conceptual content; these changes led him to become the hub of intercultural activity that could be developed in the center of compulsory education. Since this article is to show how to organize the music room (space, materials, attitudes, values and contents) for the musical education process becomes an educational process intercultural. In conclusion, also include a didactic-based cooperative work as the main tool of intercultural musical educational intervention. We started from the consideration that communication between cultures is a reality thanks to the practice of musical performance that is cooperative in nature, and thanks to the critical study of musical language understood as a universal language of communication between peoples

Key words: Cultural diversity, intercultural, music, music education 
Bernabé, M. M. (2014). Pautas organizativas del aula de Música de secundaria para atender a la diversidad cultural: propuestas didácticas. Espiral. Cuadernos del Profesorado, 7(14), 25-36. Disponible en: http://www.cepcuevasolula.es/espiral.

Fecha de recepción: 16/10/2012

Fecha de aceptación: 11/01/2014
Enviar correspondencia a: mdmbernabe@ucam.edu

\section{1.- INTRODUCCIÓN}

El fenómeno migratorio trajo consigo contactos culturales que provocaron una necesaria revisión de los contenidos curriculares en la legislación educativa. Cuando el número de alumnado extranjero en las aulas fue visto como una realidad (en muchas ocasiones problemática) y cuando éstos comenzaron a demandar una educación de calidad y en condiciones de igualdad, todas las asignaturas del currículo educativo de Educación Secundaria Obligatoria (ESO) se vieron obligadas a ofrecer una serie de cambios en sus contenidos, principalmente, para que esa educación de calidad fuese extensible a todos los educandos. En esta línea de cambios conceptuales, la asignatura de Música fue una de las que mejor supo adaptarse y aprovechar la nueva situación, debido a las características intrínsecas de su propia práctica interpretativa y educativa; pasó entonces a ser el centro neurálgico de la posible actividad intercultural del centro de secundaria.

La Música es un "producto" que muestra los valores, las creencias y los sentimientos de una cultura, si se parte de la consideración de De Moya, Hernández, y Hernández (2010) de que la educación es una poderosa herramienta de transmisión de valores. Se trata de una actividad que manifiesta sentimientos, pensamientos y costumbres de un pueblo (Venturi, 2004); de manera que, desde este punto de vista, la clase de Música de ESO puede convertirse en ese centro neurálgico del trabajo de la interculturalidad, tal como ha defendido Ruiz (2007) con su propuesta de educación musical intercultural para esta etapa educativa que utiliza como principal herramienta la composición; también, es la protagonista en determinadas actividades propuestas de la Cruz Roja Española (2009) y de Blasco, Bueno y Torregrosa (2004) para las tutorías.

En la ESO, el alumnado se encuentra inmerso en la adolescencia, situación que per se dificulta las relaciones sociales entre los educandos, y que viene a unirse al "problema" de la diversidad cultural (Pliego y Valero, 2011). De acuerdo con nuestra experiencia con este perfil de alumnado y en este nivel educativo, se puede decir que gran parte de las dificultades que puedan darse en el aula se deben más a cuestiones relativas a las relaciones sociales entre adolescentes con sobrecarga hormonal que al denominado "choque" cultural. La adolescencia es una etapa evolutiva dedicada a la construcción de la propia identidad (Fernández, 2005), y la falta de reconocimiento a la identidad de esa minoría cultural puede llevarle a rechazarla y a perderla, lo que provocará dificultades en su proceso formativo. Y, para procurar evitarlas, el centro educativo debe convertir todos sus espacios en puntos de participación real y efectiva de estas culturas minoritarias, en puntos de expresión e intercambio cultural, que contribuyan al desarrollo de una sociedad efectivamente respetuosa con la pluralidad cultural (Ramírez, 2006).

La diversidad cultural debe aprovecharse para construir un currículo "interculturalizado" (Leiva, 2011a), es decir, un currículo que refleje aportaciones culturales en un nivel conceptual, pero también procedimientos y objetivos actitudinales especiales que garanticen la consecución de los mismos (Bernabé, 2012) y se cubran las necesidades de los diversos grupos culturales de un país. Para responder a esa realidad sociocultural del país y de esta asignatura musical, la legislación educativa planteó una serie de cambios significativos que se centraron en la inclusión de contenidos de tipo conceptual y a pequeñas referencias a la importancia de educar interculturalmente. Las actitudes y los valores de tipo intercultural no quedaban realmente reflejados junto a esa ampliación/variación de contenidos teórico-prácticos, debido a que no se sustentaban con los correspondientes contenidos procedimentales y actitudinales, así como no se adecuaron los criterios de evaluación a esa nueva realidad educativa intercultural. De acuerdo con Touriñán (2008), se puede afirmar que la educación obligatoria ha reducido el proceso educativo intercultural al ámbito cognitivo, ya que sólo se han 
incluido nuevos contenidos culturales comprendidos como la representación totalitaria de la cultura "del otro"; al tiempo que se han obviado los valores, el trabajo de la aceptación y el respeto a la diversidad como camino hacia la igualdad de derechos. Pero, para lograr esos objetivos o intenciones interculturales, es muy importante conseguir la adecuada formación del profesorado que debe promoverse para mejorar la situación social del país. El profesorado debe ser consciente de que no basta con la inclusión de contenidos de otras culturas, sino que debe aprender a desarrollar diferentes estrategias educativas adecuadas a las necesidades de ese nuevo alumnado (Leiva y Merino, 2007) y, por supuesto, de sus familias, agentes claves para la comunidad educativa intercultural (Leiva, 2011b).

En epígrafes posteriores se mostrará que la interpretación de música de otros pueblos debe completarse con un trabajo teórico enfocado desde los principios de la educación intercultural, porque su desarrollo se concibe como una mejora de las actividades que constituyen el PEC (Proyecto Educativo de Centro) (Cobo, Motos, García, y Moral, 2009). Estos principios repercutirán en la distribución del instrumental de las clases y del resto de elementos del aula educativa. En estas páginas se pretende mostrar cómo debe organizarse el aula musical para que el proceso de enseñanza/aprendizaje se convierta en un procedimiento educativo intercultural, en el que la comunicación entre culturas sea una realidad gracias a la comprensión del lenguaje musical como lenguaje universal de comunicación intercultural.

\section{2.- CONTEXTOS EDUCATIVOS PLURICULTURALES}

Se puede afirmar que la Historia Mundial es la historia de las migraciones (FETE-UGT, 2011). Puede considerarse que la perspectiva dinámica de la cultura y las culturas que introduce la interculturalidad (Fundación Secretariado Gitano, 2007), se perdió con el paso de los siglos; aunque, no debería olvidarse que la diversidad puede considerarse la norma (Colectivo Yedra, 2009), es decir, es más común que la unicidad, ya que todos somos diferentes incluso dentro de una pretendida homogeneidad.

La propia diversidad de culturas del país desembocó, tras el fin de la dictadura franquista, en un intento de revalorización de los elementos tradicionales a través del currículo educativo, para conseguir que los educandos se convirtiesen en ciudadanos de pleno derecho. Principalmente, se pretendía garantizar el conocimiento de la propia cultura para evitar la homogeneización del país; dicha uniformización ya se había presenciado con su fundación como Estado moderno al ocultar/eliminar/suprimir la pluriculturalidad existente (Fundación Secretariado Gitano, 2007). Este tipo de actitudes llevó a la enseñanza española a una gran rigidez y uniformidad ante su propia diversidad cultural "exterior" (Ramírez, 2006); es decir, se defendían las características propias de las diferentes comunidades autonómicas, pero costó mucho incluir elementos de otras culturas presentes en el aula. Desde 2006, la legislación educativa muestra cómo los contenidos incluidos en la asignatura de Música en secundaria contribuyen a comprenderla como "bien cultural y reflejo de la historia" y como "recuperación y afianzamiento de la identidad cultural de las regiones y grupos con características propias” (Lorenzo y Espejo, 2011, p. 38-39).

La llegada masiva de familias inmigrantes trajo una demanda de una educación de calidad para todos; situación que supuso la modificación de los contenidos curriculares de Secundaria. En este sentido, fueron asignaturas como Música o Ciencias Sociales-Historia las que más cambios sufrieron; aunque, las referencias a valores y actitudes estaban más presentes en la asignatura de Música. Según Leiva (2011a), aprovechar esa diversidad desde el punto de vista educativo pasa por reconocerla como algo común e imprescindible en el diseño de las propuestas de intervención educativas. Resulta curioso que la administración educativa haya sido tan poco previsora en sus cambios legislativos en este sentido, cuando la pluriculturalidad ha sido un fenómeno constante en el territorio peninsular desde hace siglos.

El colectivo docente debe tomar consciencia de que todo proceso educativo en contextos pluriculturales no tendrá éxito si no cuenta con un desarrollo de contenidos actitudinales y procedimentales acordes con los contenidos conceptuales trabajados. Se debe insistir en la importancia del retorno a programar diferenciando los tres tipos de contenidos (conceptuales, procedimentales y 
actitudinales) (Bernabé, 2011 y 2012), ya que si bien las competencias han conseguido un primer plano, no debe olvidarse que todas ellas se caracterizan por la promoción de valores, de actitudes... En síntesis, se trataría de conservar y ampliar esa antigua división de los contenidos con las denominadas competencias básicas, ya que los contenidos actitudinales no deberían quedar reducidos a una mera referencia en los objetivos relacionada con el aprecio y el respeto a la diversidad cultural. De este modo, el centro educativo quedaría convertido en un espacio de encuentro y de enriquecimiento de los diferentes modelos culturales (Ramírez, 2006), un lugar donde intercambiar y reflexionar, que facilite la integración del educando y su familia (FETE-UGT, 2009).

El centro educativo se convertirá en el lugar donde todos los implicados serán conscientes de que deben mostrarse receptivos ante las culturas respectivas; ya que no sólo debe exigirse a la cultura de acogida que reconozca la minoritaria sino que la minoritaria debe plantearse el valor de la cultura de acogida y el valor de tomar aspectos de la misma. Entonces, desde una perspectiva educativa intercultural se pretenderá dotar al alumnado de herramientas para construir su identidad de forma crítica, libre y responsable (Carbonell, 2000). Aunque, ¿por qué escoger un modelo educativo intercultural para esta clase de Música? Porque la educación intercultural favorece el diálogo, la convivencia, el sentimiento de igualdad, y el respeto a la diferencia (González, 2010); también prepara para el desarrollo de una convivencia pacífica, gracias al reconocimiento del otro y a la elección libre de valores que se realiza (Touriñán, 2008); además, supone una predisposición afectiva positiva (De Moya, Hernández y Hernández, 2010) hacia “el otro". Aunque, principalmente, la importancia de seguir una línea educativa intercultural se debe a que los principales distintivos de la educación intercultural responden o pueden organizarse bajo los cuatro pilares de la educación que establece la UNESCO (2006): enseñar a saber-conocer, enseñar a hacer, enseñar a vivir juntos, y enseñar a ser.

El reto de la interculturalidad consiste en formar al individuo como un ser capaz de combinar la cultura propia con aquella que tiene próxima, pudiendo comprender y desplazarse de una a otra sin problemas (Touriñán, 2008). Aquí, la utilización de la Música encuentra su justificación, ya que el estudio de la historia de las características musicales que se realiza durante la ESO permite profundizar en ella y comprender los diferentes elementos prestados y asimilados como propios por parte de cada cultura. Es decir, que la Música ofrece una "visión” de las relaciones culturales porque es fruto de esa interacción cultural que pregona la educación intercultural. Ésta implica interacción, intercambio, interdependencia, reconocimiento; y, su objetivo es la construcción de una cultura compartida que muestre aquellos elementos que pueden ofrecer cada una de las culturas en contacto, convirtiéndose los elementos en "nuestros" y dejando de ser "míos" y "tuyos".

El aula de Música como espacio educativo intercultural e permitiría crear un espacio social conjunto y regido por normas construidas entre todos, fruto de la negociación (Carbonell, 2000). Sin embargo, sólo podrá construirse una cultura común y compartida si se reflexiona sobre la cultura propia; de hecho, la interculturalidad es concebida como una propuesta educativa reflexiva (Leiva, 2008). En esta dirección, la Música es un ejemplo y un instrumento de enriquecimiento y reflexión: por ejemplo, la música de Granados muestra toda la fuerza de la cultura andaluza, pero gran parte de esos elementos que se defienden como propios son resultado de fusiones y contactos derivados de invasiones o migraciones vividas en siglos pasados.

El enriquecimiento que aporta el interculturalismo supone una superación del multiculturalismo, ya que se trabaja la igualdad de todas las culturas y el reconocimiento de sus valores (Rodríguez, 2006). Pero, nada de esto será posible si el centro educativo no apuesta por el diálogo, la cooperación y el intercambio (Leiva, 2008). Es esta opción educativa intercultural la que permitirá enfrentarse a los retos educativos resultado de esta sociedad pluricultural (Ramírez, 2006); puesto que la educación intercultural reconoce como legítima la diversidad cultural (Muñoz y Menchén, 2002) y, por consiguiente, prepara al alumnado para hacer frente a la misma. La educación intercultural debe caracterizarse por la convicción de que hay más igualdad que diferencia entre las diferentes culturas (Carbonell, 2000) y, a partir de ahí, debe enfocarse el proceso educativo que ya no podrá ser entendido como un intento de compensar déficits porque el concepto de "compensación" implica más negatividad que elementos positivos. 
El aula de secundaria y la asignatura de Música permiten desarrollar cómodamente los principios que la UNESCO (2006) considera característicos de la educación intercultural: posibilita una educación de calidad para todos, respeta la identidad cultural del alumnado, provee a éstos de conocimientos culturales y actitudes necesarias para participar activamente en la sociedad de acogida, y le provee de conocimientos y actitudes para contribuir al respeto y al entendimiento entre los diferentes grupos culturales, religiosos, étnicos y sociales. De acuerdo con Touriñán (2008), la interculturalidad implica la "voluntad de" y un compromiso moral, puesto que si vamos a educar tomando como punto de partida simplemente la ampliación de contenidos conceptuales, éstos no van a garantizar que comprendas al otro ni te relaciones de una forma positiva y afectiva con él. Sin embargo, si se toma como excusa la interpretación de una partitura africana para comentar los elementos que ésta tiene en común con la música española, ésta se convertirá en una herramienta de reflexión, cambio e intercambio, y entonces sí podrá mejorarse la relación con "el otro” y se allanará el camino hacia la interculturalidad.

\section{3.- UN “NUEVO” ESPACIO DE TRABAJO DE LA INTERCULTURALIDAD: LA CLASE DE MÚSICA}

La asignatura de Música es un espacio idóneo para trabajar la interculturalidad dentro del centro de ESO. Es más, debe considerase un "elemento" imprescindible actualmente porque la educación intercultural es la llave del entendimiento y del intercambio cultural, tan necesarios para esta pluricultural sociedad. Es decir, se precisa de algo más que del conocimiento y las interrelaciones con otras culturas, también se precisa el autoconocimiento y el replanteamiento de la cultura propia para poder comprenderse y, por tanto, comprender al otro, cuestiones características de esta "opción" educativa. Entonces, la Música es una herramienta idónea para trabajar la interculturalidad porque todas las culturas se expresan musicalmente (González, 2010); además, es transmisora de información y de acontecimientos de las diferentes comunidades. Su supuesta "abstracción” física, su falta de corporeidad facilita una comprensión universal entre todos los oyentes, puesto que su finalidad no está cerrada, y ahí precisamente radica su belleza y su como instrumento educativo y comunicativo entre culturas.

El espacio musical (en primaria y secundaria) es muy importante porque todo el alumnado se encuentra presente, incluso aquel alumnado que es separado en otras materias porque precisa refuerzo. Todos comparten ese espacio comunicativo y constructivo porque la Música es un lenguaje no verbal que comunica sin necesidad de un lenguaje verbal; de manera que, aquellos que no comprenden la lengua vehicular del centro no se sentirán excluidos ante actividades como los juegos de preguntarespuesta o las ruedas de improvisación de percusión corporal o instrumental. La meta principal del proceso educativo es garantizar la integración social, y si el alumnado no es separado del resto del aula se verá favorecida su sociabilidad y se convertirán en significativos aprendizajes que podrían dejar de serlo para este perfil de alumnado (Carbonell, 2000).

La ESO ha promovido el estudio de la música tradicional de la comunidad o región propia, como punto de partida para la reflexión cultural, para ahondar en la cultura de pertenencia. Pero, esa reflexión cultural pretendida debería enfocarse hacia la similitud de elementos entre las diferentes culturas estudiadas $\mathrm{y}$, posteriormente, hacia la diferencia cultural, como primer paso para la apreciación del otro; es decir, que el aula de Música tiene que considerarse un punto de encuentro cultural (De Moya, Hernández, y Hernández, 2010) y de trabajo de valores como el respeto (a otras músicas), la tolerancia (ante el resultado musical del otro) y la igualdad (al analizar diferentes músicas y comprobar cómo se construyen a partir de elementos comunes y compartidos) (Leiva y Merino, 2007). La clase de Música posibilitará todo esto si se sigue ese planteamiento educativo intercultural, en el que la diferencia cultural implique riqueza y no división (Muñoz y Menchén, 2002), y que tenga como principal herramienta el trabajo cooperativo para conseguir la inclusividad en el centro educativo (Leiva, 2011b).

Es muy importante que la Historia de la Música, la propia partitura musical y la improvisación, se conviertan en instrumentos de búsqueda de similitudes entre músicas de otras 
culturas, más que reducirse a un trabajo de búsqueda de elementos nuevos o a un trabajo de interpretación. Desde estas páginas estamos defendiendo que no se insista en señalar la diferencia, sino en buscar elementos comunes para analizar las posibles diferencias que ya no serían vistas como tan numerosas (Bernabé, 2011). Es obvio que el mundo es una marea de gente heterogénea, pero al mismo tiempo y de acuerdo con una canción del grupo catalán Macaco, todos vibramos al mismo compás. Ese "compás” debe ayudarnos a crear una cultura compartida, a re-construir una cultura compartida, que nunca será igual a la de otras zonas del mundo que también traten de conseguir un desarrollo intercultural.

En ese sentido de no marcar la diferencia, insiste Touriñán (2008), quien considera que se puede desarrollar un reduccionismo, la pervivencia del poder de la cultura dominante que no es "la diferente”. De ahí que hayamos insistido en señalar las similitudes, en trabajar los elementos compartidos que inviten a repensar la propia cultura para poder comprender los elementos diferentes y crear algo común. El estudio, el análisis y la interpretación de la Música, permite estudiar "al otro" desde un punto de vista ameno, al tiempo que permite conocerse mejor, hecho que ayudará a comprender lo parecidos que somos los unos a los otros.

La interculturalidad trabajada mediante las diferentes herramientas que ofrece la Música permite encontrar valores universales compartidos, dialogar sobre ellos y sobre la igualdad entre las personas (De Moya, Hernández, y Hernández, 2010). No puede olvidarse que la Música muestra fusiones de diferentes zonas del mundo, hecho que parecen aceptar todos los oyentes; invita a sentir emociones "exclusivas" de todos los seres humanos, y nuevamente nadie se extraña ante la universalidad de los sentimientos que se comparten cuando se escucha... Básicamente, la educación intercultural promueve el aprendizaje de la tolerancia no como valor sino como necesidad (Vila, 2009) para nuestra sociedad actual.

Antes de ofrecer actividades musicales interculturales que pueden trabajarse a lo largo de cualquier curso de ESO, deben concretarse una serie de "normas" para garantizar que el desarrollo de éstas cumpla con los principios de la educación intercultural ya citados. Es decir, si queremos conseguir actividades musicales que promuevan actitudes interculturales de acuerdo con lo establecido en la legislación vigente para esta etapa educativa, debemos organizar el aula y los diferentes materiales y estrategias de una forma determinada.

En primer lugar, el aula debe organizarse para que el alumnado no deba desplazarse a otra aula diferente para interpretar una partitura musical porque esto implica un planteamiento organizativo muy dividido: la teoría va por un lado y, la práctica, por otro. Esa organización no contribuye a mostrar el aula musical como un punto de encuentro, de intercambio, en el que práctica y teoría-historia están estrechamente ligadas. El mantener esa separación contribuye a mostrar que esta clase es otro espacio más en el que la teoría está recogida en un libro y es inamovible, mientras que la práctica tiene algo que ver con esos elementos estudiados, pero forma parte de una puntuación final separada. Por supuesto, no todos los centros cuentan con aulas de música en las que el instrumental esté separado, pero es una tónica bastante común. Sin embargo, aunque el instrumental esté incluido en una única aula, deben evitarse los espacios diferenciados (uno de explicación-mutismo del alumno, y otro de interpretación-conversación del alumnado), porque el alumno debería estar siempre en contacto con los instrumentos.

Si la clase de Música de Secundaria se orientase al aprendizaje de la Música desde una perspectiva intercultural, en la que el análisis de características musicales se enfocase como punto de partida para comprender las similitudes y las diferencias entre culturas, se estarían aprendiendo una serie de contenidos conceptuales musicales y toda una serie de elementos transversales que les llevarían a comprenderse y a comprender al otro. Es decir, orientemos esta clase a conseguir unos valores interculturales a través de un estudio razonado de diferentes músicas y de la reflexión sobre los elementos de la música propia. Leiva (2011a) apoyaría esta línea al considerar que cuando se educa interculturalmente para evitar la exclusión, se debe promover un currículo alejado del uso exclusivo del libro de texto. 
Estas consideraciones de convertir la clase de Música en un espacio de formación global no son compartidas por todos los profesionales de la enseñanza musical de secundaria, tal como hemos podido comprobar tras participar en debates de diferentes congresos de educación musical. Sin embargo, ¿el análisis de partituras musicales y la búsqueda de diferencias y similitudes, no lleva a la comprensión y memorización de los contenidos teóricos? Entonces, concretemos. El educando estará siempre ante un instrumento que debe ir cambiando cada semana para que se trabaje el valor de compartir con "el otro", así como de respetar los materiales que todos deben disfrutar. El docente presentará las características de cada período o de cada artista mientras el alumnado cuenta con una partitura para proceder a la búsqueda de cada elemento que se vaya comentando; se trataría de comentar cada uno de ellos y de buscar similitudes con canciones de otros lugares del mundo o con canciones actuales si se está estudiando música clásica.

En segundo lugar, para trabajar interculturalmente la organización de pupitres más adecuada sería el formato de orquesta. Es decir, lo más adecuado es que se dispongan como un semicírculo y en primera posición los carrillones, después los xilófonos y luego los metalófonos; aunque, en caso de contar con instrumental de pequeña percusión como panderos, cascabeles, claves, güiros, cajas chinas..., se colocarían al fondo y por sonoridades agudas a graves. Se podría considerar que así no todos tienen la misma visión, que no todos se observan, que unos pueden quejarse por estar al fondo y otros por estar los primeros... Pero, realmente, en música no se observan estas puntualizaciones porque: todos los instrumentos son imprescindibles ocupen la posición espacial que ocupen, cada instrumento aporta una sonoridad especial que lo hace único y diferente, y la distribución espacial que sitúa a los instrumentos más graves siempre al fondo y los más agudos delante tiene un sentido y una razón puramente musicales. Es decir, se responde a un resultado interpretativo que mostrará los frutos del respeto a la interpretación y la posición del otro; de ahí, la necesidad de trabajar lo más prácticamente posible y de orientar estas sesiones al trabajo de valores y competencias.

Con estas pautas se pretende evitar la caída en las actividades denominadas "interculturales", que confunden la interculturalidad con el folklorismo, cuya confusión debe evitarse (Carbonell, 2000; Bernabé 2011). Siguiendo a Samper (2011), se trataría de incorporar repertorios de culturas tradicionales desechadas, a las que se suman las obras clásicas y populares modernas, que quizá sean las que más unan al alumnado procedente de diferentes partes del mundo.

En tercer lugar, los contenidos conceptuales deben centrarse en la presentación de las características histórico-musicales y en el estudio de sus principales figuras. No sólo pueden trabajarse las características de la música romántica con Chopin, puesto que se puede aprender a buscar elementos de ésta en la música tradicional polaca de la misma época e, incluso, en la música polaca moderna actual. El docente cuando muestra un elemento estilístico concreto (concepto) que los alumnos deben buscar en la partitura con su interpretación (procedimiento) se estará intentando mostrar qué implica o implicó dicha característica en el pensamiento de la época y qué supone para ellos hoy día de acuerdo con su contexto (actitudes). Con este trabajo en el aula no puede más que concluirse cada unidad didáctica con un test en el que se evalúe su grado de asimilación de los valores interculturales y de las competencias básicas.

La inclusión de contenidos musicales de otras culturas no debe favorecer únicamente el conocimiento de otras realidades, cuestión que es primordial para la convivencia y el entendimiento (Cobo, Motos, García, y Moral, 2009), es decir, que no debe quedarse en una aproximación folclorista, igual que el estudio de la música tradicional de cada comunidad no debe convertirse en un instrumento político, sino que el estudio de ambas debe convertirse en un estudio comparado que permita más que aproximarse a las diferencias para respetarlas, aproximarse a las similitudes para comprender la igualdad entre ellas. Primero debemos respetar que todos somos iguales, bastante más de lo que pueda considerarse y, posteriormente, apreciar la riqueza que las diferencias aportan a unos y otros y que los convierten en únicos. En palabras de Touriñán (2008), se debe promover una educación para aprender a vivir juntos, y añadamos, revueltos.

Incluimos dos actividades (tablas 1 y 2) organizadas de acuerdo con un esquema y línea de pensamiento que hemos considerado intercultural. Por supuesto, estos puntos indicados (indicaciones 
para la evaluación intercultural y la atención específica a problemas derivados de la diversidad cultural que aparecen en las tablas 1 y 2) deben añadirse a las indicaciones de la legislación, así como a los diferentes esquemas tradicionales de unidades didácticas que puedan proponerse en el aula:

Tabla 1

Cazando estrellas

\begin{tabular}{|c|c|}
\hline Objetivos interculturales & Objetivos musicales \\
\hline $\begin{array}{l}\text { - Conocer la existencia de músicas más allá del } \\
\text { folclore. } \\
\text { - Reconocer y valorar la presencia de la diversidad en } \\
\text { nuestra vida musical cotidiana. } \\
\text { - Apreciar los elementos musicales que esos artistas } \\
\text { han aportado a la música popular urbana. } \\
\text { - Analizar musicalmente para conseguir conocer y } \\
\text { reconocer la presencia de otras culturas dentro de } \\
\text { España. }\end{array}$ & $\begin{array}{l}\text { - Distinguir los elementos constitutivos de la Música } \\
\text { (ritmo, melodía, timbre, textura, tempo...). } \\
\text { - Diferenciar las formas musicales. } \\
\text { - Escuchar y comentar diferentes estilos musicales del } \\
\text { pasado y del presente. } \\
\text { - Utilizar las nuevas tecnologías para obtener } \\
\text { información. } \\
\text { - Valorar otras manifestaciones musicales diferentes a la } \\
\text { propia. }\end{array}$ \\
\hline \multicolumn{2}{|c|}{ Contenidos } \\
\hline Conceptuales & Procedimentales \\
\hline $\begin{array}{ll}\text { - Elementos constitutivos de la } & \text { - Respeto a diferer } \\
\text { Música. } & \text { musicales de la Hi } \\
\text { - Las formas musicales. } & \text { Música. } \\
& - \text { Valoración } \\
& \text { manifestaciones m }\end{array}$ & $\begin{array}{ll}\text { tes formas } & \text { - Creación de temas sobre diferentes } \\
\text { storia de la } & \text { grupos/cantantes. } \\
& \text { - Exposición colectiva (cooperativa) oral. } \\
\text { de otras } & \text { - Uso de las nuevas tecnologías en el } \\
\text { usicales. } & \text { proceso de búsqueda de información sobre } \\
& \text { los diversos cantantes/grupos elegidos. }\end{array}$ \\
\hline
\end{tabular}

\section{Competencias básicas}

Principalmente se trabajan:

- Tratamiento de la información y competencia digital: se precisa del manejo de las TIC’s. Por extensión, la proximidad a información "exterior" y otras interpretaciones de una realidad musical común contribuirá a enriquecer sus puntos de vista por el intercambio y a respetar otras opciones sobre un mismo hecho.

- Autonomía e iniciativa personal: la libertad a la hora de la organización y estructuración de sus trabajos, les permitirá comprender mejor la importancia del trabajo. Por extensión, aprenderán a trabajar cooperativamente y a regular sus propios esfuerzos para comprender cuánto les cuesta a los demás el mismo proceso.

\section{Desarrollo}

Esta actividad precisa del manejo de las nuevas tecnologías, porque el alumnado debe conseguir información sobre famosos cantantes que escuchan en sus emisoras preferidas, como punto de partida para aprender qué es la tolerancia cultural y el respeto a la diferencia. La clase deberá realizar una lista de cinco de sus grupos o cantantes favoritos. Después, deberán buscar información sobre ellos en Internet, para poder responder a las siguientes preguntas planteadas por el docente: influencias de su música, sus ritmos más frecuentes, el estilo o estilos en que se mueve, lugar de origen (nacimiento y crianza), ámbito en que suelen moverse (giras mundiales, etc.). Una vez contestadas estas cuestiones, deberán realizar una presentación sobre cada uno de sus "ídolos" musicales, delante de toda la clase.

\section{Atención específica ante problemas de aprendizaje relacionados con la diversidad cultural}

Si los alumnos no se manejan en la lengua vehicular del centro o tienen dificultades para escribirla, se podrán realizar las preguntas de forma oral. Mediante esas búsquedas podrán mejorar su comprensión de la lengua, además de que podrán buscar información de esos grupos en sus lenguas maternas y, después, solicitar una traducción de éstas.

\section{Indicaciones para la evaluación intercultural}

Es muy importante que se evalúen las actitudes y no sólo la asimilación de conceptos y procedimientos. De esta forma se estará teniendo en cuenta que las actitudes de respeto y reconocimiento ante la realidad del otro, están asumidas y asimiladas. 
Tabla 2

Nuestra voz

Objetivos interculturales

Objetivos musicales \begin{tabular}{ll}
\hline - Aunar el sentimiento grupal mediante el trabajo & - Desarrollar la técnica vocal e instrumental. \\
cooperativo. & - Interpretar piezas vocales e instrumentales de diferentes. \\
- Improvisar musicalmente para respetar la & - Asumir responsabilidades en la interpretación grupal. \\
enriquecedora diferencia. & - Improvisar vocalmente respuestas a estímulos musicales y \\
- Trabajar con otras grafías para respetar los $\begin{array}{l}\text { extramusicales. } \\
\text { diferentes lenguajes musicales. }\end{array}$ & $\begin{array}{l}\text { - Utilizar notación musical y grafías no convencionales para } \\
\text { representar la música. }\end{array}$ \\
\hline
\end{tabular}

\begin{tabular}{|c|c|c|}
\hline \multicolumn{3}{|c|}{ Contenidos } \\
\hline Conceptuales & Actitudinales & Procedimentales \\
\hline $\begin{array}{l}\text { - Técnica del instrumento de } \\
\text { percusión de sonido indeterminado. } \\
\text { - Grafías convencionales y no } \\
\text { convencionales. }\end{array}$ & $\begin{array}{l}\text { - Asunción de responsabilidades en } \\
\text { el proceso de interpretación. } \\
\text { - Respeto en los momentos de } \\
\text { improvisación vocal y corporal. }\end{array}$ & $\begin{array}{l}\text { - Creación de musicogramas. } \\
\text { - Improvisación vocal y corporal. }\end{array}$ \\
\hline & Competencias básicas & \\
\hline
\end{tabular}

Principalmente se trabajan:

- Aprender a aprender: el proceso de libertad creadora de sus propios musicogramas e improvisación de elementos constitutivos les lleva a adquirir esta competencia, al tiempo que aprenden a respetar la del otro por lo que ésta les aporta. Por extensión, respetan “al otro” y se inicia el camino de la tolerancia.

- Cultural y artística: no es necesario insistir en la adquisición de ésta. Por extensión, conocen las aportaciones de otras culturas y sus interpretaciones de los elementos musicales comunes, de modo que intercambian y experimentan con lo que se les ofrece para incorporarlo a su propio bagaje.

- Interacción con el mundo físico: deben tomar diferentes elementos de su realidad para ofrecérselos al oyente. Por extensión, las diversas interpretaciones del entorno llevarán a interiorizarlas y a comprender la realidad de una forma diferente, más próxima a la "del otro".

\section{Desarrollo}

Con una respiración diafragmática previa, se realizan ejercicios de calentamiento, porque van a interpretar musicogramas que ellos mismos realizarán con grafías alternativas y de sus propias creaciones musicales. Podrán utilizar monosílabos y diferentes sonidos vocales, así como tendrán que combinar el silencio como elemento de escucha hacia el otro.

\section{Atención específica ante problemas de aprendizaje relacionados con la diversidad cultural}

Los niños con problemas de comunicación derivados de su desconocimiento de la lengua, no tendrán problemas en este ejercicio, puesto que la interpretación de las diferentes grafías es tan abierta como la interpretación musical.

\section{Indicaciones para la evaluación intercultural}

Es muy importante que se evalúen las actitudes y no sólo la asimilación de conceptos y procedimientos. De esta forma se estará teniendo en cuenta que las actitudes de respeto y reconocimiento ante la realidad del otro, están asumidas y asimiladas.

Tal como se deduce tras la lectura de estas dos pequeñas propuestas, la única variante con respecto a una unidad didáctica "normal" es que se han añadido unos objetivos interculturales (véanse Tablas 1 y 2), así como unas indicaciones para atender a esa diversidad cultural que van a contribuir a mejorar, al mismo tiempo, el proceso de enseñanza/aprendizaje del resto del alumnado. La Música es la única asignatura de todo el currículo de ESO que permite trabajar las ocho competencias básicas en cada una de sus actividades; sin embargo, en el desarrollo ofrecido sólo se han comentado aquellas que se potencian en mayor medida, así como su interpretación desde el punto de vista de aquello que aportan a la competencia intercultural del alumnado. Es muy importante la división de los contenidos y la inclusión de las competencias básicas desde el punto de vista de lo que pueden aportar al tratamiento de la diversidad cultural, y, en definitiva, a la adquisición de una competencia intercultural que es la más importante de las competencias que se precisan actualmente para convivir y compartir en sociedad. 


\section{4.- CONCLUSIONES}

Esta organización intercultural del aula de Música permitirá adquirir valores como el respeto a la producción del otro, al silencio que implica escuchar al otro... Por supuesto, es necesario trabajar otras músicas porque esto implica invitar a la reflexión cultural, un intercambio de elementos musicales que puedan fundirse en un nuevo resultado, sin caer en un proceso de memorización que no resulta enriquecedor a nivel intercultural. Es decir, debe evitarse el desarrollo de experiencias interculturales puntuales, porque entonces sí podrá decirse que el centro educativo es un espacio de trabajo y consecución de la interculturalidad, con todo lo que ésta implica. Leiva (2011 b) considera que la institución escolar es un lugar fundamental de formación para la convivencia intercultural; y, añadimos, que puede decirse que el aula de Música de Secundaria, tanto por los contenidos como por el desarrollo madurativo que se vivencia, se puede convertir en ese espacio en el que el alumnado tome conciencia sobre lo importante que es aprender a convivir, el hecho de considerarse ciudadano del lugar que se habita y ciudadano del lugar del que se viene (FETE-UGT, 2011), tomando prestados valores y conocimientos de ambas ciudadanías que te hagan mejor ciudadano en ambas culturas.

Algunos autores como De Moya, Hernández y Hernández (2010) han considerado que el aprendizaje musical debe centrarse en el componente social y dejar de lado la tendencia tradicionalista academicista; también, Carbonell (2000) considera que en la educación obligatoria las actividades de enseñanza/aprendizaje deben interpretarse como medios al servicio de la socialización y de la educación global. Se ha partido de una consideración muy lógica y que no menosprecia o disminuye la importancia que los contenidos teóricos musicales pueden tener: el hecho de que la Música es la única asignatura del currículo con la que se pueden trabajar perfectamente, y sin recurrir a rebuscadas interpretaciones, todas las denominadas Competencias Básicas.

$\mathrm{Si}$ se establecen relaciones entre los contenidos musicales, una serie de actitudes interculturales y sus respectivos procedimientos en el mismo sentido, estaremos desarrollando en el alumnado un aprendizaje teórico musical y la adquisición de diferentes competencias imprescindibles para su desarrollo social. Es decir, el éxito de todo proceso educativo que cuente con la presencia de hijos de inmigrantes, dependerá de las actitudes que se desarrollen en el aula (Leiva, 2011 b), de ahí nuestra insistencia en el trabajo y evaluación de las actitudes.

No debe obviarse la poderosa función social y cultural de la Música (De Moya, Hernández y Hernández, 2010), ya que su práctica cooperativa, y sus interrelaciones e interdependencia, la convierten en una herramienta social por excelencia dentro del centro educativo. Así, el aula musical, precisamente por esas características tan repetidas, debe enfocarse a la adquisición de la competencia intercultural, principalmente. Dicha interculturalidad es muy necesaria para la sociedad actual, caracterizada por el culto a la inmediatez y a la homogeneidad, que no hace sino aumentar las diferencias de clases y casi exigir una homogeneidad cultural. Esa interculturalidad debe ser entendida como una reflexión e intercambio de valores y actitudes, que puede llevarse a cabo en el aula musical gracias a sus prácticas cooperativas, de respeto a la producción del compañero, de intercambio y fusión de elementos propios y ajenos...

La educación musical es un proceso tan global que contribuye como ninguna otra a la formación de ciudadanos libres, democráticos, y respetuosos con "el otro". Sin embargo, esta última etapa obligatoria deberá convertirse en el punto final de construcción de una ciudadanía intercultural que se caracterice por asumir la existencia de colectivos distintos que construyan un proyecto común cohesionado (Folgueiras, Massot, y Sabariego, 2008); y, todo esto se verá facilitado por las características intrínsecas de la asignatura de Música en ESO. Sin embargo, nada de todo lo anteriormente citado será posible si los educadores no se muestran receptivos ante dos ideas (Rodríguez, 2006): lo local repercute en lo internacional y los problemas deben entenderse de forma global. Principalmente, el docente debe estar formado para mostrar cómo entre las diversas culturas que habitan el territorio existe una interconexión real; interconexión que se vuelve una realidad cuando se estudia la asignatura de Música.

En definitiva, y aunque no convirtamos el aula de Música en un espacio único y completo de trabajo de actitudes, valores y competencias, resulta lícito considerar que una organización 
intercultural de este aula, tal y como se ha propuesto, permitirá a los docentes trabajar la interculturalidad tan necesaria para que la sociedad actual no olvide la presencia "del otro". Y, al mismo tiempo, se plantea una reconstrucción cultural compartida, que muestra que la identidad implica un proceso dinámico y en movimiento continuo (Samper, 2011); realidad que aparece perfectamente reflejada y recogida a lo largo de toda la Historia de la Música, de ahí la importancia de enfocar su práctica y estudio desde la perspectiva intercultural.

\section{5.- REFERENCIAS}

Aneas, M. A. (2005). Competencia intercultural, concepto, efectos e implicaciones en el ejercicio de la ciudadanía. Revista Iberoamericana de Educación [en línea], 35(5). Disponible en: http://www.rieoei.org/psi edu21.htm [Consulta: 13 de marzo].

Batelaan, P. y Coomans, F. (1995). Bases internacionales para la educación intercultural incluyendo la educación antirracista y sobre los derechos humanos. Disponible en: http://www.aulaintercultural.org/IMG/pdf/bases_internac.pdf [Consulta: 2010, 3 de marzo].

Bernabé, M. (2011). La Educación Intercultural en el aula de Música. Unidades didácticas interculturales para Educación Primaria. Saarbrücken: Editorial Académica Española.

Bernabé, M. (2012). Cómo organizar el proceso de enseñanza musical de forma intercultural: propuestas para trabajar interculturalmente en el área de primaria. DEDiCA. Revista de Educaçao e Humanidades, 2(1), 235-248.

Blasco, J. L., Bueno, V., y Torregrosa, D. (2004). Educación intercultural. Propuestas para la tutoría. Valencia: Generalidad Valenciana.

Carbonell, F. (2000). Decálogo para una educación intercultural. Monitor educador, 90, 32-39.

Cobo, M. F., Motos, M. A., García, A. J., y Moral, G. (2009). Análisis de las actividades realizadas en los proyectos de interculturalidad desarrollados en las provincias de Almería y Málaga. Espiral. Cuadernos del profesorado, 2 (3), 104-110.

Colectivo Yedra (2009). Convivencia escolar. Madrid: Cyan, Proyectos y Producciones Editoriales, S.A.

Cruz Roja Española (2009). Cuaderno de actividades. Una propuesta para trabajar la Interculturalidad. Madrid: Cruz Roja Española.

De Moya, M. V., Hernández, J. R., y Hernández, J. A. (2010). Experiencia intercultural en el aula "La música nos une”. Música y Educación, 84, 18-28.

Fernández, J. M. (2005). Inmigración y educación en el contexto español: un desafío educativo. Revista Iberoamericana de Educación, 36(11). Disponible http://www.rieoei.org/deloslectores/1041Batanero.PDF [Consulta: 2010, 14 de mayo].

FETE-UGT (2009). La gestión de centros interculturales. Guía del Profesorado. Madrid: Cyan, Proyectos y Producciones Editoriales S.A.

FETE-UGT (2011). 20 Ideas para construir la interculturalidad y prevenir el racismo en educación. Madrid: Secretaría de Políticas Sociales de FETE-UGT y Departamento de Migraciones Confederal de UGT.

Folgueiras, P., Massot, I., y Sabariego, M. (2008). La ciudadanía activa e intercultural en alumnado de la ESO. Revista Interuniversitaria de Formación del Profesorado, 27 (11), 19-28.

Fundación Secretariado Gitano (2007). Retos en los contextos multiculturales. Competencias interculturales y resolución de conflictos. Madrid: Fundación Secretariado Gitano.

González, O. (2010). Una experiencia de curriculum musical intercultural. Música y Educación, 81, 18-33.

Leiva, J. J. (2008). Interculturalidad, gestión de la convivencia y diversidad cultural en la escuela: un estudio de las actitudes del profesorado. Revista Iberoamericana de Educación [en línea], 46(2). Disponible en: http://www.rieoei.org/deloslectores/2297Leiva2.pdf [Consulta: 2009, 10 de junio].

Leiva, J. J. (2011a). La educación intercultural en una encrucijada de caminos: reflexiones pedagógicas para la construcción de una escuela intercultural. Espiral. Cuadernos del profesorado, 4(7), 43-56.

Leiva, J. J. (2011b). La educación intercultural: un compromiso educativo para construir una escuela sin exclusiones. Revista Iberoamericana de Educación [en línea], 56(1). Disponible en: http://www.rieoei.org/deloslectores/4242Olivencia.pdf [Consulta: 2012, 20 de marzo].

Leiva, J. J. y Merino, D. (2007). La función docente en contextos de diversidad cultural. Revista Iberoamericana de Educación [en línea], 41 (2). Disponible en: http://www.rieoei.org/deloslectores/1425Leiva.pdf [Consulta: 2009, 10 de marzo].

Lorenzo, O. y Espejo, J. A. (2011). Folclore musical en las aulas de primaria y secundaria. Música y Educación, 87, 36-47.

Muñoz, A. y Menchén, F. (2002). Una perspectiva creativa de la educación intercultural: enfoques y modelos. Creatividad y Sociedad, 2, 33-40. 
Pliego, N. y Valero, M. (2011). Alumnos inmigrantes en España: una realidad creciente. Hekademos. Revista Educativa Digital, 8, 77-90.

Ramírez, F. (2006). Educación intercultural: una respuesta a las sociedades multiculturales del siglo XXI. Disponible en: http://www.aulaintercultural.org/article.php3?id_article=641 [Consulta: 2010, 3 de marzo].

Rodríguez, M. (2006). El interculturalismo, tema de nuestro tiempo. Revista Interuniversitaria de Formación de Profesorado, 1(20), 39-60.

Rojas, G. (2003). Estrategias para fomentar actitudes interculturales positivas en el aula. Aldaba: revista del Centro Asociado de la UNED de Melilla, 29, 71-87.

Ruiz, V. J. (2007). Música y Diversidad Socio-Cultural en ESO: La Composición Musical, un Punto de Encuentro. Disponible en: http://www.intercentres.edu.gva.es/iesleonardodavinci/premios-yreconocimientos/Muscia-2007.pdf [Consulta: 2010, 3 de marzo].

Samper, A. (2011). Educación musical a nivel superior e interculturalidad en el siglo XXI: nuevas epistemologías, nuevas aproximaciones didácticas. El Artista, 8, 297-316.

Sánchez, S. (2003). Interculturalidad, inmigración y educación. Aldaba: revista del Centro Asociado de la UNED de Melilla, 29, 13-32.

Touriñán, J. M. (2008). Educación en valores, educación intercultural y formación para la convivencia pacífica. La Coruña: Netbiblo.

UNESCO (2006). Guidelines on Intercultural Education. París: UNESCO.

Venturi, L. (2004). Historia de la crítica de arte. Barcelona: Random House Mondadori, S. A.

Vila, E. (2009). Educar para la tolerancia, educar para la convivencia. Espiral. Cuadernos del profesorado, 2(4), 43-47.

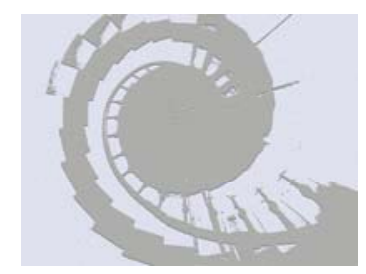

